\title{
Surgical management of cystic lesions of the pancreas: a single-centre experience
}

\author{
Gabriela Beatriz SIA ${ }^{1}$, Pedro França da Costa SOARES ${ }^{2}$, Martinho Antonio GESTIC² , Elinton Adami CHAIM $^{2}$, \\ Francisco CALLEJAS-NETO ${ }^{2}$ and Everton CAZZO $^{1}$
}

\begin{abstract}
Background - Cystic lesions of the pancreas represent a group of pancreatic diseases with great histological heterogeneity, varying from benign lesions, some of them with malignant potential, to overt malignant lesions. Objective - To describe the cases of cystic lesions of the pancreas which underwent surgical intervention at a tertiary university hospital. Methods - This is a retrospective population-based study (historical cohort) which was carried out enrolling individuals attended at the Outpatient service of Pancreas Surgery of the Hospital de Clinicas of Unicamp. The individuals underwent surgical procedures performed from January 2012 through December 2016. Results - In the period evaluated, 39 cases of cystic lesions of the pancreas which underwent surgery were identified, $26(66.6 \%)$ of which were female. The average age at diagnosis was $47.4 \pm 16.4$ years (range, 18-73). In regards to symptoms, 35 (89.7\%) were symptomatic. The average length of hospital stay was 10 days (range 4-76). Surgeries performed to treat the lesions depended on the localization and type of the lesions: cystojejunostomy (41\%), distal pancreatectomy (36\%), pancreaticoduodenectomy (15.4\%), drainage of ruptured and/or infected pseudocyst (5.2\%) and central pancreatectomy (2.6\%). Conclusion - Cystic lesions of the pancreas are a group of lesions with a highly varying presentation and diagnostic approach and may require an also highly variable surgical treatment. An appropriate preoperative imaging diagnosis is essential for their management.
\end{abstract}

HEADINGS - Neoplasms, cystic, mucinous, and serous. Serous cystadenoma. Mucinous cystadenoma. Pancreatic pseudocyst. Pancreatic neoplasms.

\section{INTRODUCTION}

Cystic lesions of the pancreas (CLPs) represent a group of pancreatic diseases with great histological heterogeneity, varying from benign lesions, some of them with malignant potential, to overt malignant lesions. These lesions can be classified into three major groups: pseudocysts, non-neoplastic cysts and cystic neoplasms of the pancreas. With the exception of the pancreatic pseudocyst, cystic neoplasms of the pancreas occur more frequently than their non-neoplastic counterparts. The incidence of these lesions has increased over recent decades, a fact apparently related to the progress of imaging methods; it is estimated that they affect approximately $0.7 \%$ to $24.3 \%$ of the population ${ }^{(1,2)}$.

Pancreatic pseudocysts are the most frequent CLPs, corresponding to $80 \%$ of them. This type of lesion may be one of the complications of acute pancreatitis, chronic pancreatitis and pancreatic trauma. Simple pancreatic cysts are considered rare, usually asymptomatic and incidentally diagnosed. The cystic neoplasms of the pancreas correspond to a group of diseases with peculiar characteristics and are classified as serous cystic neoplasm, mucinous cystic neoplasm (with significant malignant potential), and intraductal papillary mucinous neoplasm (IPMN) types I (main duct), II (branch duct) and III (mixed), that are considered pre-malignant lesions as well. Solid pseudopapillary pancreatic neoplasm, also known as Frantz's tumor, is characterized by pancreatic lesions that may also contain cystic spaces or regions of cystic degeneration ${ }^{(1-5)}$.
The symptoms of CLPs vary according to the type and localization of the lesion, ranging from asymptomatic, secondary manifestations to extrinsic compression until the presence of abdominal pain, weight loss, low back pain, nausea, constipation, diarrhea, abdominal distension, among others. The diagnosis of a pancreatic cystic lesion can be poorly made by means of clinical assessment and fundamentally requires imaging methods. Computed tomography (CT) is the most commonly used imaging test for the diagnosis of cystic lesions, as it allows the identification and characterization of the lesion. Magnetic resonance imaging (MRI) is another alternative with the advantage of better evaluating the ductal anatomy of the pancreas and not requiring the use of iodinated contrast. More recently, the use of endoscopic ultrasound scan (EUS) has considerably improved the etiological diagnosis of these lesions and allows fine-needle aspiration of the cystic fluid content for assessment of cytological and biochemical examinations, especially tumor markers such as carcinoembryonic antigen (CEA) and CA 19-9. The diagnosis and classification of the type of pancreatic cystic lesion is very important to evaluate the degree of malignancy of the lesion and to define the best therapeutic option and best prognosis for these patients $\mathrm{s}^{(2,3,5)}$.

The treatment of CLPs is directly related to the type of lesion. Some of them, such as incidentally found asymptomatic cystic serous neoplasms, only require careful clinical and radiologic following. Bypasses by endoscopy or surgery may be indicated for pseudocysts depending on the symptoms produced by them.

Declared conflict of interest of all authors: none

Disclosure of funding: no funding received

${ }^{1}$ Pontifícia Universidade Católica de Campinas (PUCCAMP), Faculdade de Medicina, Campinas, SP, Brasil. ${ }^{2}$ Universidade Estadual de Campinas (UNICAMP), Faculdade de Ciências Médicas, Departamento de Cirurgia, Campinas, SP, Brasil.

Research performed at: UNICAMP, Faculdade de Ciências Médicas, Departamento de Cirurgia, Campinas, SP, Brasil.

Corresponding author: Everton Cazzo. Orcid: https://orcid.org/0000-0002-5804-1580. E-mail: notrevezzo@yahoo.com.br, evertoncazzo@yahoo.com.br 
Conventional segmental or even total pancreatic resections are indicated in the case of cystic lesions depending on the characterization of the lesion ${ }^{(1-5)}$.

In Brazil, recent publications on CLPs are limited to literature reviews, case series and reports ${ }^{(6,7)}$. This study aims to describe the cases of CLPs which underwent surgical intervention at a tertiary university hospital.

\section{METHODS}

This is a retrospective population-based study (historical cohort) which was carried out enrolling individuals attended at the Outpatient service of Pancreas Surgery of the Hospital de Clínicas of Unicamp. The research protocol was evaluated by the local Research Ethics Committee and approved under the reference number 2.318.647/CAAE: 72405517.5.0000.5404/Unicamp.

The individuals underwent surgical procedures performed from January 2012 through December 2016. Data were obtained through medical records and outpatient worksheets. Individuals were identified according to the electronic database of surgical procedures of the hospital and histopathological examinations were checked to confirm the cystic nature of the lesions. Included in this study were individuals over 18 years old which underwent surgical treatment for cystic lesions of the pancreas, with histopathological diagnosis confirmed according to World Health Organization (WHO) classification criteria ${ }^{(8)}$ and of both genders. All individuals which underwent cystojejunostomy or drainage of infected/ruptured pseudocysts had a small portion of the cyst's capsule resected and sent to biopsy to exclude the possibility of a neoplasm. Individuals included in vulnerable groups (those with mental disabilities, institutionalized) and those with incomplete data in the health records were excluded from the sample.

The variables evaluated in this study were: age (expressed in full years at the time of treatment), gender (expressed in male and female), histopathological type, symptoms at diagnosis, preoperative imaging, type of surgery, surgical complications, and surgical mortality.

\section{Statistical analysis}

Data were expressed as means \pm standard deviation. For the execution of descriptive statistical analysis, it was used Microsoft Excel $^{\circledR} 2016$.

\section{RESULTS}

In the period evaluated, 39 cases of CLPs which underwent surgery were identified, $26(66.6 \%)$ of which were female. The average age at diagnosis was 47.4 years (range, 18-73). In regards to symptoms, $35(89.7 \%)$ were symptomatic, presenting abdominal pain $(77 \%)$, weight loss $(41 \%)$, nausea and vomiting $(38.5 \%)$, and abdominal distension (30.8\%) as the commonest symptoms. TABLE 1 details the main symptoms observed.

The most prevalent localization of the CLPs was the bodytail transition of the pancreas, accounting for $35.9 \%$ of the cases, whereas pancreatic head lesions were found in $20.5 \%$ of the cases. FIGURE 1 details the localization of the lesions. The preoperative diagnosis was made mainly through ultrasound, computed tomography, nuclear magnetic resonance and/or magnetic resonance as described in TABLE 2.
TABLE 1. Symptomatology of the individuals who underwent surgery for cystic lesions of the pancreas.

\begin{tabular}{lcc}
\hline & $\mathbf{N}$ & $\%$ \\
\hline Asymptomatic & 4 & 10.3 \\
Abdominal Pain & 30 & 77 \\
Weight loss & 16 & 41 \\
Nausea and vomiting & 15 & 38.5 \\
Jaundice & 5 & 12.8 \\
Choluria & 4 & 10.2 \\
Fecal acholia & 3 & 7.7 \\
Itch & 2 & 5.1 \\
Inappetence & 4 & 10.2 \\
Abdominal distension & 12 & 30.8 \\
Dyspepsia & 3 & 7.7 \\
Diarrhea & 3 & 7.7 \\
Constipation & 4 & 10.2 \\
\hline
\end{tabular}

$\mathrm{N}$ : number of individuals.

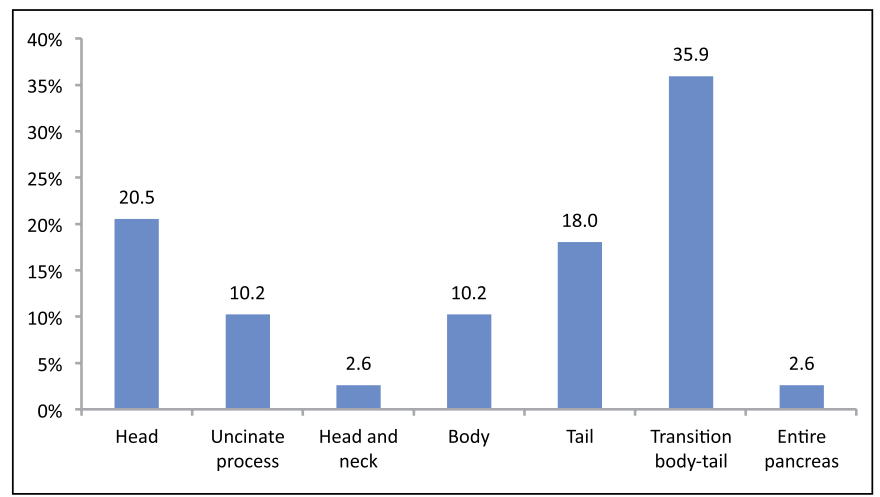

FIGURE 1. Frequency of cystic lesions of the pancreas according to localization.

TABLE 2. Imaging methods used to diagnose cystic lesions of the pancreas.

\begin{tabular}{lc}
\hline Method & $\mathbf{N}(\%)$ \\
\hline US & $22(56.4)$ \\
EUS & $18(46.1)$ \\
CT & $32(82)$ \\
MRI & $21(54)$
\end{tabular}

US: ultrasound scan; EUS: endoscopic ultrasound scan; CT: computed tomography; MRI: magnetic resonance imaging; $\mathrm{N}$ : number of individuals.

The average length of hospital stay was 10 days (range 4-76). Surgeries performed to treat the lesions depended on the localization and type of the lesions. The surgeries performed were cystojejunostomy $(41 \%)$, distal pancreatectomy $(36 \%)$, pancreaticoduodenectomy (15.4\%), drainage of ruptured and/or infected pseudocyst $(5.2 \%)$ and central pancreatectomy $(2.6 \%)$. Surgical complications were seen in $17(43.6 \%)$ patients; pancreatic fistula $(10.2 \%)$, intestinal subocclusion $(7.7 \%)$ were the most common. The surgical procedure associated with a higher morbidity was pancreaticoduodenectomy $(50 \%)$. Overall surgical mortality was $5.1 \%$. TABLE 3 details the morbidity observed. 
TABLE 3. Complications after surgical resection of cystic lesions of the pancreas.

\begin{tabular}{lcc}
\hline & $\mathbf{N}$ & $\%$ \\
\hline Hospital-acquired infection & 3 & 7.7 \\
Incisional hernia & 3 & 7.7 \\
Wound infection & 4 & 10.2 \\
Pancreatic leak & 4 & 10.2 \\
Intestinal obstruction & 3 & 7.7 \\
Septic shock & 1 & 2.6 \\
Hypovolemic shock & 4 & 10.2 \\
Acute renal failure & 1 & 2.6 \\
Pulmonary thromboembolism & 1 & 2.6 \\
\hline
\end{tabular}

$\mathrm{N}$ : number of individuals.

In regards to the histopathological evaluation, there were 18 cases of pancreatic pseudocyst (46.1\%). TABLE 4 describes the histopathological findings of the entire sample. Three patients $(50 \%)$ presented invasive carcinoma associated with IPMN; the three individuals presented the same histology (ductal adenocarcinoma) and TNM staging (T1N0); there was no late cancer-related mortality after a mean follow-up of $28.7 \pm 9$ months. None of the individuals with mucinous neoplasms presented an invasive car-

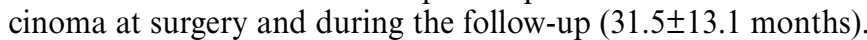
The complete demographic profile of the patients according to the histopathological findings is detailed in TABLE 5.

TABLE 4. Histopathological analysis of cystic lesions of the pancreas.

\begin{tabular}{lll}
\hline Subtype & N & $\%$ \\
\hline Pseudocyst & 18 & 46.1 \\
IPMN & 6 & 15.4 \\
Serous neoplasm & 6 & 15.4 \\
Mucinous neoplasm & 5 & 12.8 \\
Frantz's tumor & 4 & 10.2 \\
\hline
\end{tabular}

IPMN: intraductal papillary mucinous neoplasm; N: number of individuals.

\section{DISCUSSION}

CLPs have a varied prevalence in the population. Considering only pseudocysts, the overall prevalence is significant due to its relationship with pancreatitis, which is a disease that presents a somewhat common occurrence. However, a much lower prevalence is found when analyzing only pancreatic neoplastic cystic lesions ( $1 \%$ to $10 \%$ of pancreatic neoplasms). These, despite their rarity, account for about $30 \%$ of pancreatic resections ${ }^{(2,3,5-9)}$. The incidence of CLPs is increasing (2), mainly due to advances in imaging technology and increased access to computed tomography (CT) and magnetic resonance imaging (MRI).

The predominance of the diseases occurred in females $(66.6 \%)$ and the most common histopathological diagnosis was pseudocyst; these epidemiological and histological profiles are compatible with those of the existing literature, since cystic neoplastic lesions are more frequent in the female population. In summary, the majority of the neoplastic cystic lesions (serous neoplasms, mucinous neoplasms and Frantz's tumors) were mostly observed in females, whereas pseudocysts presented no predominance and IPMNs were more common among men; Frantz's tumor predominated in young adults, whereas the others were more frequent among middle-aged to elderly individuals. Usually, the Frantz's tumor is 10 times more frequent in women ${ }^{(9)}$. Regarding the clinical presentation of patients at diagnosis, the majority $(89.7 \%)$ were symptomatic, differently from what has been reported in other series with $40 \%$ to $75 \%$ of cases being asymptomatic ${ }^{(2-4,7,9)}$; it is very likely that this was due to the fact that all individuals of this series underwent surgery and thus the surgical indication biased the results. Therefore, the majority of the individuals in the current series due presented large-volume lesions diagnosed after causing mass effect and consequently abdominal pain, nausea, vomiting, weight loss and abdominal distension. These more prevalent symptoms are consistent with those cases that have already been described, especially in the presence of extensive and palpable mass in the physical examination and previous pancreatitis associated with pseudocyst formation ${ }^{(10)}$. US, CT, MRI, and EUS were performed for the imaging diagnosis. US is useful for distinguishing solid from cystic lesions, presents low cost and is highly accessible; however, it is operator-dependent, does not provide further information on the nature of the lesion and may be ineffective when there is interposition of intestinal loops on the pancreas ${ }^{(2-5)}$. EUS is a diagnostic method with a high

TABLE 5. Epidemiologic profile of the patients according to histopathological subtype.

\begin{tabular}{|c|c|c|c|c|c|}
\hline & Pseudocyst & Frantz's tumor & Serous neoplasm & Mucinous neoplasm & IPMN \\
\hline \multicolumn{6}{|l|}{ Sex } \\
\hline Male & $50 \%$ & - & - & - & $66.6 \%$ \\
\hline Female & $50 \%$ & $100 \%$ & $100 \%$ & $100 \%$ & $33.3 \%$ \\
\hline \multicolumn{6}{|l|}{ Symptoms } \\
\hline Asymptomatic & - & $25 \%$ & $20 \%$ & $20 \%$ & $16.6 \%$ \\
\hline Symptomatic & $100 \%$ & $75 \%$ & $83.3 \%$ & $80 \%$ & $83.3 \%$ \\
\hline
\end{tabular}

IPMN: intraductal papillary mucinous neoplasm. 
sensitivity for cystic lesions with at least 2 high-risk factors, such as size greater than $3 \mathrm{~cm}$, dilation of the main pancreatic duct or the presence of an associated solid component; it allows fine-needle aspiration of the cystic fluid and subsequent analysis that may aid in the diagnosis of these lesions ${ }^{(6)}$; however, it was scarcely used in this series, which reflects the low availability of this method in our country and especially in the public health system. According to the guideline of the American Gastroenterology Association (AGA 2015), patients with no relevant results in the EUS and fine needle puncture should perform MRI after one year to guarantee no chance of malignancy of the lesion ${ }^{(11,12)}$. Hence, it may be pointed that US is useful for gross detection and/or screening of lesions, whereas CT and/or MRI are enough to diagnose and indicate the appropriate therapy for the majority of the cases of CLPs, albeit EUS may provide relevant and essential information for those cases whose characterization was not appropriate by means of those more available methods.

The CLPs of the present study were mostly in the body-tail transition $(35.9 \%)$, followed by head $(20.5 \%)$ and tail $(18 \%)$. A French study by Gaujoux et al. presented the pancreatic head $(47 \%-48 \%)$ as the most prevalent, followed by body involvement (26\%-28\%); however, this study only divided the location of the cysts into pancreatic head, body and tail ${ }^{(10)}$.

According to the 2015 AGA guideline, the diagnosis and management of cystic pancreatic lesions, asymptomatic patients must undergo surgical excision of the lesion when they present a solid component and dilation of the pancreatic duct and/or risk factors in EUS and needle puncture ${ }^{(11,12)}$. Allen emphasizes that surgical resection of the lesion should be reserved for cases of presumed precancerous cysts due to their size, solid component and/or dilation of the main duct, when there is concern about the development of malignancy ${ }^{(4,13)}$. To appropriately identify and propose the adequate therapy for CLPs is relevant for both general physicians and specialists. Given their heterogeneity, CLPs may represent from innocuous findings at imaging examinations that only require cautious following to more aggressive diseases that lead to complex surgeries. Different guidelines are available but so far no optimal diagnostic or therapeutic algorithm exists. In general, mucinous neoplasms and main-duct IPMNs are always considered for surgery due to its high malignant potential. Frantz's tumors are also considered for resection for the majority of the cases, since it is considered a neoplasm of uncertain behavior, as well as it usually reaches large volumes and causes symptoms due to extrinsic compression of adjacent organs. In contrast, serous neoplasms are only considered for resection whenever they become highly symptomatic due to mass effect, which is unlikely to happen. In regards to branch-duct IPMNs, the surgical indication is warranted in an individual basis, since their behavior is not as clearly aggressive as the main-duct type. Pseudocysts usually need surgical intervention when they reach high volumes and lead to clinical symptoms due to the compression of near organs. In view of this, all of the patients in the current series were surgically treated, due to symptoms, risk of cancer and/or a high degree of suspicion for malignancy ${ }^{(14-17)}$.
The surgical mortality rate in this study was 5.1\% (two patients); both deaths were caused by postoperative sepsis related to surgical complications, one after a cystojejunostomy due to a pseudocyst, another one after a pancreaticoduodenectomy due to IPMN-related invasive cancer. Pancreatic fistula and wound infection were the most common complications among our patients, which is comparable to other series. The mortality and surgical complication rates of the current study were comparable with those of Reames et al. ${ }^{(9)}$; however, they were higher than those of the study carried out in 2011 by Gaujoux ${ }^{(10)}$. Both morbidity and mortality were more associated with complications of the surgical procedures and/or the clinical status of the patients than with the nature of the lesions ${ }^{(17)}$.

This study presents some limitations that need to be addressed. Firstly, its retrospective design may lead to data of poorer quality. Moreover, due to the nature of the series, enrolling only surgical patients, it suffers from selection bias, since a number of patients who presented non-surgical cystic lesions were not included. Nevertheless, given the scarcity of local data in regards to this group of diseases, the results observed are significant and provide relevant evidence in regards to the approach of CLPs, since they present a series from a high-volume public hospital. The strength of this casuistry is to show the distribution of a group of diseases that is difficult to appropriately diagnose and even more difficult to define the adequate treatment in a high-volume university hospital. This casuistry is more recent than other previously published and was collected after the consolidation of the imaging diagnosis of intraductal papillary mucinous neoplasms and a more deep understanding of their risk.

\section{CONCLUSION}

CLPs are a group of lesions with a highly varying presentation and diagnostic approach and may require an also highly variable surgical treatment. An appropriate preoperative imaging diagnosis is essential for their management.

\section{Statement of informed consent}

Informed consent was obtained from all individual participants included in the study.

\section{Statement of human and animal rights}

All procedures performed in studies involving human participants were in accordance with the ethical standards of the institutional and/or national research committee and with the 1964 Helsinki declaration and its later amendments or comparable ethical standards.

\section{Authors' contribution}

Sia GB collected the data and wrote the first draft of the study. Soares PFC provided clinical assistance for the individuals enrolled in the study. Gestic MA, Chaim EA, and Callejas-Neto $\mathrm{F}$ contributed relevant intellectual inserts and provided critical revision. Cazzo E designed the study and wrote substantial portions of the study. 
Sia GB, Soares PFC, Gestic MA, Chaim EA, Callejas-Neto F, Cazzo E. Tratamento cirúrgico de lesões císticas do pâncreas: uma experiência unicêntrica. Arq Gastroenterol. 2018;55(4):412-6.

RESUMO - Contexto - As lesões císticas do pâncreas representam um grupo de doenças pancreáticas com grande heterogeneidade histológica, variando desde lesões benignas, algumas com potencial pré-maligno, até outras degeneradas para formas malignas. Objetivo - Descrever os casos de LCPs submetidos à intervenção cirúrgica em um hospital universitário terciário. Métodos - Trata-se de um estudo retrospectivo populacional (coorte histórica) realizado com a participação de indivíduos atendidos no Ambulatório de Cirurgia do Pâncreas do Hospital de Clínicas da Unicamp. Os indivíduos foram submetidos a procedimentos cirúrgicos realizados no período de janeiro de 2012 a dezembro de 2016. Resultados - No período avaliado, foram identificados 39 casos de lesões císticas do pâncreas operados, sendo $26(66,6 \%)$ do sexo feminino. A idade média no diagnóstico foi de 47,4£16,4 anos. Em relação aos sintomas, 35 (89,7\%) eram sintomáticos. O tempo médio de internação foi de 10 dias (variação de 4-76). As cirurgias realizadas para o tratamento das lesões dependeram da localização e do tipo das lesões: derivação pseudocisto-jejunal (41\%), pancreatectomia distal (36\%), pancreaticoduodenectomia $(15,4 \%)$, drenagem de pseudocistos rotos e/ou infectados $(5,2 \%)$ e pancreatectomia central $(2,6 \%)$. Conclusão - As lesões císticas do pâncreas são um grupo de lesões cuja apresentação e abordagem diagnóstica são altamente heterogêneas e que podem requerer um tratamento cirúrgico altamente complexo e variável. Um diagnóstico pré-operatório adequado é essencial para definir o seu tratamento.

DESCRITORES - Neoplasias císticas, mucinosas e serosas. Cistadenoma seroso. Cistadenoma mucinoso. Pseudocisto pancreático. Neoplasias pancreáticas.

\section{REFERENCES}

1. Brugge WR. Diagnosis and management of cystic lesions of the pancreas. $\mathbf{J}$ Gastrointest Oncol. 2015;6:375-88.

2. Goh BK, Tan YM, Chung YF, Chow PK, Ong HS, Lim DT, et al. Non-neoplastic cystic and cystic-like lesions of the pancreas: may mimic pancreatic cystic neoplasms. ANZ J Surg. 2006;76:325-31.

3. Jani N, Bani Hani M, Schulick RD, Hruban RH, Cunningham SC. Diagnosis and management of cystic lesions of the pancreas. Diagn Ther Endosc. 2011;2011:478913.

4. Allen PJ. The diagnosis and management of cystic lesions of the pancreas. Chin Clin Oncol. 2017;6(6):60. doi: 10.21037/cco.2017.12.05

5. de Jong K, Bruno MJ, Fockens P. Epidemiology, diagnosis, and management of cystic lesions of the pancreas. Gastroenterol Res Pract. 2012;2012:147465.

6. Artifon ELA, Buch M, Bonini L, Aparicio DPS. Lesões Císticas do Pâncreas. GED Gastroenterol Endosc Dig. 2013;32:111-9.

7. Coelho JC, Valle CL, Ribas BM, Andriguetto LD, Claus CM. Surgical treatment of cystic neoplasms of the pancreas. Arq Gastroenterol. 2010;47:135-40.

8. Levy MJ. Pancreatic cysts. Gastrointest Endosc. 2009;69:S110-S116.

9. Reames BN, Scally CP, Frankel TL, Dimick JB, Nathan H. National trends in resection of cystic lesions of the Pancreas. HPB. 2016;18:375-82.

10. Gaujoux S, Brennan MF, Gonen M, D’Angelica MI, DeMatteo R, Fong Y. Cystic Lesions of the Pancreas: Changes in the Presentation and Management of 1,424 Patients at a Single Institution over a 15-Year Time Period. J Am Coll Surg. 2011;212:590-600
11. Vege SS, Ziring B, Jain R, Moayyedi P; Clinical Guidelines Committee; American Gastroenterology Association. American Gastroenterological Association Institute Guideline on the Diagnosis and Management of Asymptomatic Neoplastic Pancreatic Cysts. Gastroenterology. 2015;148:819-22.

12. Scheiman, J.M., Hwang, J.H., Moayyedi, P. American Gastroenterological Association Technical Review on the Diagnosis and Management of Asymptomatic Neoplastic Pancreatic Cysts. Gastroenterology. 2015; 148:824-48.

13. Allen PJ. Cystic Lesions of the Pancreas: Observe or Operate. Indian J Surg 2015;77:393-4.

14. Cazzo E, Apodaca-Rueda M, Gestic MA, Chaim FHM, Saito HPA, Utrini MP, et al. Management of pancreaticopleural fistulas secondary to chronic pancreatitis. Arq Bras Cir Dig. 2017;30:225-8.

15. Bauer, F. Pancreatic Cystic Lesions: Diagnostic, Management and Indications for Operation. Part I. Chirurgia (Bucur). 2017;112:97-109.

16. Huffman BM, Westin G, Alsidawi S, Alberts SR, Nagorney DM, Halfdanarson TR, Mahipal A. Survival and Prognostic Factors in Patients With Solid Pseudopapillary Neoplasms of the Pancreas. Pancreas. 2018;47:1003-7.

17. Apodaca-Rueda M, Chaim FHM, Garcia MDS, Saito HPA, Gestic MA, Utrini MP, et al. Solitary pancreatic metastasis from breast cancer: case report and review of literature. Sao Paulo Med J. 2017 Nov 6:0. doi: 10.1590/1516 3180.2017.0144260617. 